\title{
The effect of optimism bias on time preference
}

\author{
Tal Shavit ${ }^{*}$ \\ The School of Business Administration. The College of Management Academic Studies. Rishon-Le'Zion, Israel
}

Received: 6 June 2013

Revised: 16 September 2013

Accepted: 17 September 2013

\begin{abstract}
This paper examines the effect of optimism bias on monetary time preference and risk tolerance. The results of a survey show that preference towards the present increases with optimism bias. I argue that the factor which affects time preference is the individual's concern regarding future events, as measured by optimism bias.
\end{abstract}

Keywords: time preference, discount rates, time and risk perception JEL Classification Codes: D90, D91

\section{Introduction}

In economic research, time preference is measured by subjective discount rate (SDR), the rate at which an individual trades current value for future outcome (e.g. Thaler, 1981; Benzion et al., 1989). Whereas some individuals opt for immediate payment, others are more patient and willing to wait longer. In general, an individual who values the present more than the future will have higher time subjective discount rate (SDR). One of the explanations for the existence of SDR is that delaying rewards is risky because it increases the possibility that something may prevent payment (e.g. Stevenson, 1986; Myerson et al., 2003). Keren and Roelofsma (1995) and Ahlbrecht and Weber (1997) suggest that discounting for riskless payoffs reflects the uncertainty encapsulated in future payoffs. There is some new evidence showing that SDRs are higher in risky environment where people feel that their life is at risk (Chao et al., 2009; Lahav et al., 2011).

One of the main behavioral factors related to risk perception and economic behavior is optimism bias. Weinstein (1980) reported that students tend to believe that they are less likely than their peers to experience negative events (see also Wenglert and Rosén, 2000). He suggests that people are "optimism biased" or overly optimistic since they see themselves as facing less than average risk, compared to the risk they perceive is faced by members of a group to which they belong (see also Quadrel et al., 1993; Weinstein, 2000). Optimism bias or

*Corresponding author. E-mail: shavittal@gmail.com.

Citation: Shavit, T. (2013) The effect of optimism bias on time preference, Economics and Business Letters, 2(3), 128-133. 
over optimism is used in many economic and finance studies to explain irrational behavior (e.g. Odean, 1998; Malmendier and Tate, 2005). However to the best of my knowledge, no previous study has tested the relationship between optimism bias and time preference. The basic hypothesis is that people who are overly optimistic or show a higher optimism bias will have higher preference towards the future since they are more optimistic regarding the uncertainty encapsulated in future payoffs. Specifically, the estimation of the possibility that something may prevent payment should be lower for people who are overly optimistic or show a higher optimism bias. To test this hypothesis I measured individuals' optimism bias by asking them for their assessments about the chances of experiencing a negative event in the future relative to others. I also measured time preference by using SDR for different periods and monetary risk aversion. The 128 participants completed a survey about their time preference, optimism bias and risk aversion. Then correlations between the measures were tested. This paper is the first to show the correlation between optimism bias and time preference.

\section{The Survey}

\subsection{Research population}

The participants in the study were $128 \mathrm{MBA}$ students from a college of management academic studies in Israel (mean age $=29.4,44 \%$ males). The survey took place in a classroom prior to a lecture. Participants were asked to participate in a study in the field of decision making. Those who agreed were given a survey including several financial decisions related to their monetary time preference and risk attitude, as well as an optimism bias measure. They were asked for their best estimates, and told there was no one "correct" answer, so their answers should reflect only their own personal preferences.

\subsection{Design and procedure}

Time preference: In the first part, participants were asked to indicate the amount of compensation they would want if they traded receiving a certain amount immediately for receiving a higher amount later. Specifically, participants were informed they could receive $x$ New Israeli Shekels (NIS ${ }^{1}$ ) immediately, and were instructed to write down the amount they would ask to receive at some time in the future $(t)$ rather than receiving $x$ today. The time periods $(t)$ were: one week, four weeks and three months and the amount was NIS 5000. For example:

You are going to receive NIS 5000 immediately. Instead, we are offering you the option of receiving a different amount 4 weeks from today. What is the minimum amount you are willing to accept 4 weeks from now in order to postpone receipt of the sum?

Instead of NIS $\underline{\mathbf{5 0 0 0}}$ today, I am willing to accept NIS in four weeks.

Comparative optimism bias: I measured individual's assessment about their personal chance of experiencing a negative event in the future relative to others (Lerner et al., 2003). Participants were asked to indicate how likely it was that they themselves might experience each of three risky events ${ }^{2}$ : getting the flu, being a victim of a violent crime, and being hurt in a car accident. They were then asked to indicate how likely it was that the average Israeli would suffer each of the three risky events. The anchors for these scales were $0 \%$ (the event is impossible) and $100 \%$ (the event is certain to occur).

\footnotetext{
${ }^{1}$ At the time of the experiment, the exchange rate was about NIS $3.9=$ USD 1.

${ }^{2}$ These events were also used in Lerner et al. (2003) and in Rosenboim et al. (2012).
} 
Monetary Risk Preference: In order to measure monetary risk preferences, the survey included monetary risk preference questions. I used a 1ottery question similar to one in Booij and van Praag (2009):

Suppose you were offered a chance to participate in a lottery involving 10 participants (therefore, you have a 1:10 chance of winning). The prize to be won is NIS 10,000 in cash. What would be the maximum amount you are willing to pay for the ticket?

I am willing to pay no more than NIS in order to purchase the lottery ticket.

\section{Results}

The SDR for delaying payment was calculated as follows:

$$
\mathrm{SDR}=\left(\frac{P}{X}\right)
$$

where $\mathrm{P}$ is the amount the subject is willing to accept for delaying the receipt of amount $\mathrm{X}$ today. The average SDRs are: for one week, 6.9\% (STDV $=9.5 \%$ ) for four weeks, $20.6 \%$ $(\mathrm{STDV}=27.6 \%)$ and for three months $62.6 \%(\mathrm{STDV}=113.9 \%)$. The monetary risk tolerance measure was calculated by the WTP for the lottery, meaning that a lower WTP indicates a lower risk tolerance or higher risk aversion. The average WTP is 279.5 (STDV = 351.6). Optimism bias was estimated for each risky item by calculating the difference between estimates for the chance of an average Israeli versus the self being harmed by each of the risks (Weinstein 1980). Next, I calculated the average optimism bias for the three risky item to get an optimism bias index (the Cronbach's $\alpha$ is 0.83). The average optimism bias index is $11.38 \%(\mathrm{STDV}=19.09 \%)$ and significantly different from zero $\left(\mathrm{t}(127)=6.75\right.$, sig $\left.^{\prime}<0.01\right)$ meaning that on average the subjects show optimism bias.

Table 1 shows the correlations between the optimism bias index and the SDRs and the risk tolerance measure.

Table 1. Correlations between optimism bias and SDRs and risk tolerance

\begin{tabular}{cc}
\hline \hline & Optimism bias \\
\hline \hline SDR - one week & $\rho=0.260($ sig' $<0.01)$ \\
SDR - four weeks & $\rho=0.245($ sig' $<0.01)$ \\
SDR - three months & $\rho=0.210($ sig' $=0.02)$ \\
Risk tolerance & $\rho=-0.187($ sig' $=0.03)$ \\
\hline \hline
\end{tabular}

Table 1 shows that optimism bias is positively correlated with the SDR, and negatively correlated with monetary risk tolerance. This means that as optimism bias increases people tendency to concentrate on the present and reduce their risk tolerance. These results are the opposite of the basic hypothesis that when people are overly optimistic they show higher preference towards the future.

\section{Discussion}

In this study, the correlation between optimism bias and time preference was tested for the first time. Although I expected to find a positive correlation between a preference towards the future and an optimism bias, the results appear to be the opposite. The explanation for these findings is based on the motivational biases reflected in an optimism bias. The research on 
risk perception distinguishes between the estimation of risk and the fear from this risk. Fischhoff et al. (2003) argue that optimism bias patterns may reflect motivational biases or the desire to feel more secure. The motivational biases influence people's judgment about the chance of facing risky event, and their estimation is swayed by the cost of the event itself. When the cost of a negative event is high, they underestimate the chance of its occurrence in order to feel more secure. Therefore, unlike risk perception which measures the individual's estimation of a future risky event, the optimism bias reflects the individual's concerns regarding the risky event and his desire to feel more secure. As concerns regarding the risky event increase, so does the optimism bias. Note that the risky events used to measure optimism bias in this paper are not directly related to expectations regarding the individual's economic state in the future. However, the risky events do reflect optimism bias which relates to uncertainty encapsulated in the future, and the possibility that something may prevent payment.

I suggest that the factor which affects time preference is the individual's motivational bias or his concern regarding future events. It is not the question of the individual's estimation regarding risky event but rather their fear of future risky events. People who show higher fear of the future will have higher preference for the present and, as a result, higher SDR. Table 1 show that people with higher optimism bias, display lower risk tolerance or higher risk aversion. This is also in line with the motivational bias, since people who wish to feel more secure (as reflected in optimism bias) will show lower tolerance towards risk.

Furthermore, I suggest that optimism bias is a good measure for intolerance of uncertainty in the future or present, and can explain risk aversion and time preference. More research is needed in order to support the findings of this paper, and demonstrate that the positive relationship between optimism bias and present-biased preferences is a robust phenomenon. For example, testing the relationship in different group of respondents (people of different ages or from different regions). It would also be possible to manipulate the degree of optimism bias experimentally, and then to check whether participants who were manipulated to show a greater degree of optimism also demonstrate a greater present-biased preferences than those who were manipulated to show a less degree of optimism. It would be also interesting for future research to examine what drives the unexpected positive relationship between optimism bias and present-biased preferences. As suggested previously, the optimism bias scale may reflect individuals' motivated perception of risk, which is derived from their fear of risky future events, rather than their optimistic estimation of future risk. To support the argument regarding the effect of the motivated perception of risk on presentbiased preferences, it is possible to test how fear of future risk combined with optimism bias affects present-biased preferences. This could be done by measuring optimism bias differently than I measured it in this paper, using positive events (people tend to believe that they are more likely than their peers to experience positive events) or by testing the subjective life expectancy relatively to the actual life expectancy (e.g., Mirowsky, 1999). In addition to optimism bias, future research could examine other individual-difference scales, and explore their relationships to optimism bias and present-biased preferences. I show that optimism bias is positively correlated with the SDR, and negatively correlated with monetary risk tolerance. This is consistent with the finding that risk tolerance is negatively correlated with presentbiased (e.g., Anderhub et al., 2001; Gerber and Rohde, 2010). However, other individualdifference scales might also influence or be influenced by either optimism bias or presentbiased preferences. For example, mood which is measured by the positive and negative affects questionnaire (PANAS) suggested by Watson et al. (1988) ${ }^{3}$.

\footnotetext{
${ }^{3}$ The positive emotions are: interested, excited, strong, enthusiastic, proud, alert, inspired, determined, attentive, active; the negative emotions are: distressed, upset, guilty, afraid, hostile, irritable, ashamed, nervous, jittery, scared.
} 
Note that present-biased preferences are very important since they affect financial and business decision making, particularly asset pricing, decisions regarding future activities and other managerial decisions (e.g., Russell, 2009; Sayman and Öncüler, 2009; Dohmen, 2011; Shavit and Adam, 2011; Chang et al., 2013).

Present-bias also affects the willingness to take loans and the willingness to save money for the short term or the long term (Meier and Sprenger, 2010). The findings of this paper indicate that present-biased is affected by optimism bias. This means that present-biased preferences might be a mediator between optimism bias and financial and business decision making.

To conclude, future research should control for optimism bias when comparing SDRs for different groups or when testing the different factors which affect time preference. Optimism bias should also be taken into consideration in theoretical research on time preference.

Acknowledgements. I would like to thank the Editor-in-Chief Francisco J. Delgado and the anonymous reviewer for comments and suggestions on the initial version. The usual disclaimer applies.

\section{References}

Anderhub, V., Gneezy, U., Guth, W. and Sonsino, D. (2001) On the interaction of risk and time preferences: An experimental study, German Economic Review, 2, 239-253.

Benzion, U., Rapoport, A. and Yagil, J. (1989) Discount rates inferred from decisions: An experimental study, Management Science, 35, 270-284.

Booij, A.S. and van Praag, B.M.S. (2009) A simultaneous approach to the estimation of risk aversion and the subjective time discount rate, Journal of Economic Behavior and Organization, 70, 374-388.

Chang, C.C., Chang, S.S., Chang, J.H. and Chien, Y.L. (2013) Which is the better option? Quicker or cheaper?, Psychology \& Marketing, 30(1), 90-101.

Chao, L.W., Szrek, H., Pereira, N.S. and Pauly, M.V. (2009) Time preference and its relationship with age, health, and survival probability, Judgment and Decision Making, 4, 1-19.

Dohmen, T., Falk, A., Huffman, D., Sunde, U., Schupp, J. and Wagner, G.G. (2011) Individual risk attitudes: measurement, determinants and behavioral consequences, Journal of the European Economic Association, 9(3), 522-550.

Fischhoff, B., Gonzalez, R.M., Lerner, J.S. and Small, D.A. (2003) Judged terror risk and proximity to the World Trade Center, Journal of Risk and Uncertainty, 26(2-3), 137-151.

Gerber, A. and Rohde, K.I. (2010) Risk and preference reversals in intertemporal choice, Journal of Economic Behavior \& Organization, 76(3), 654-668.

Lahav, E., Benzion, U. and Shavit, T. (2011) The effect of military service on soldiers' time preference: evidence from Israel, Judgment and Decision Making, 6(2), 130-138.

Lerner, J.S., Gonzalez, R.M., Small, D.A. and Fischhoff, B. (2003) Emotion and perceived risks of terrorism: a national field experiment, Psychological Science, 14, 144-150.

Malmendier, U. and Tate, G. (2005) CEO overconfidence and corporate investment, Journal of Finance, 60, 2661-2700.

Meier, S. and Sprenger, C. (2010) Present-biased preferences and credit card borrowing, American Economic Journal: Applied Economics, 2, 193-210.

Mirowsky, J. (1999) Subjective life expectancy in the US: correspondence to actuarial estimates by age, sex and race, Social Science \& Medicine, 49(7), 967-979.

Myerson, J., Green, L., Hanson, J.S., Holt, D. and Estle, S.J. (2003) Discounting delayed and probabilistic rewards: processes and traits, Journal of Economic Psychology, 24, 619-635.

Odean, T. (1998) Volume, volatility, price, and profit when all traders are above average, Journal of Finance, 53, 1887-1934. 
Quadrel, M.J., Fischhoff, B. and Davis, W. (1993) Adolescent invulnerability, American Psychologist, 48, 102-116.

Rosenboim, M., Benzion, U., Shahrabani, S. and Shavit, T. (2012) Emotions, risk perceptions and precautionary behavior under the threat of terror attacks: a field study among Israeli college students, Journal of Behavioral Decision Making, 25(3), 248-256.

Russell, J. (2009) Tenant time preference as a barrier to homeownership, Applied Economics Letters, 16(10), 1073-1077.

Sayman, S. and Öncüler, A. (2009) An investigation of time inconsistency, Management Science, 55(3), 470-482.

Shavit, T. and Adam, A.M. (2011) A preliminary exploration of the effects of rational factors and behavioral biases on the managerial choice to invest in corporate responsibility, Managerial and Decision Economics, 32(3), 205-213.

Stevenson, M.K. (1986) A discounting model for decisions with delayed positive or negative outcomes, Journal of Experimental Psychology: General, 115, 131-154.

Thaler, R.H. (1981) Some empirical evidence on dynamic inconsistency, Economic Letters, 8, 201207.

Watson, D., Clark, L.A. and Tellegen, A. (1988) Development and validation of brief measures of positive and negative affect: the PANAS scales, Journal of Personality and Social Psychology, 54(6), 1063-1070.

Wenglert, L. and Rosén, A.S. (2000) Measuring optimism-pessimism from beliefs about future events, Personality and Individual Differences, 28, 717-728.

Weinstein, N.D. (1980) Unrealistic optimism about future life events, Journal of Personality and Social Psychology, 39, 806-820.

Weinstein, N.D. (2000) Perceived probability, perceived severity, and health-protective behavior, Health Psychology, 19(1), 65-74. 